\title{
THE EFFECT OF VENESECTION AND THE POOLING OF BLOOD IN THE EXTREMITIES ON THE ATRIAL PRESSURE AND CARDIAC OUTPUT IN NORMAL SUBJECTS WITH OBSER- VATIONS ON ACUTE CIRCULATORY COLLAPSE IN THREE INSTANCES ${ }^{1}$
}

\author{
By J. V. WARREN, E. S. BRANNON, E. A. STEAD, JR., AND A. J. MERRILL \\ (From the Medical Service of Grady Hospital and the Department of Medicine, \\ Emory University School of Medicine, Atlanta)
}

(Received for publication August 24, 1944)

The mechanisms by which the body compensates for a decrease in blood volume have not been thoroughly studied in man. All physicians are aware that from 500 to $1000 \mathrm{ml}$. of blood can be removed from a person of average size without producing any symptoms, if the body is horizontal. If the blood is removed rapidly, hemodilution plays little part in the immediate adjustment. Do the arterioles constrict, maintaining the arterial pressure at a normal level at the expense of blood flow to the tissues? Is the atrial pressure maintained at the normal level by venous constriction? Or is it possible that up to a certain point, the heart can function effectively with a falling atrial pressure so that the circulation can be maintained without either arteriolar or venous constriction in spite of a moderate decrease in blood volume?

The purpose of this paper is to describe the changes in the circulation in normal subjects caused by moderate loss of blood from the body, either as the result of venesection or by pooling blood in the extremities through the application of venous tourniquets. During the experiments, acute circulatory collapse (primary shock) occurred in three instances and quantitative observations were made on the changes occurring in the circulation.

\section{METHODS}

Medical students, physicians, and paid volunteers served as subjects. They had not eaten for the preceding 12 hours and they rested in the horizontal position for at least 30 minutes before the experiment began.

1 The work described in this paper was done under a contract, recommended by the Committee on Medical Research, between the Office of Scientific Research and Development and the Emory University School of Medicine.
A catheter was introduced through the antecubital vein into the right atrium for obtaining samples of mixed venous blood and for recording the mean atrial pressure in $\mathrm{mm} . \mathrm{H}_{2} \mathrm{O}(1,2)$. In the subjects who were to be bled, a needle was placed in the femoral artery for recording the arterial pressure (3) and for obtaining samples of arterial blood. The mean arterial pressure was measured by planimetric integration of the area beneath the tracing. When tourniquets were applied to the upper thighs, arterial blood was not obtained. In these cases, a sample of atrial blood was saturated with oxygen and its oxygen content determined. It was assumed that the arterial blood was 95 per cent saturated. At the time each cardiac output was measured, the figure for the oxygen content of the arterial blood was changed in proportion to the change in the hemoglobin concentration or hematocrit reading of the sample of atrial blood used in calculating the cardiac output at that particular time. Two-minute samples of expired air were collected in Douglas bags and their oxygen and carbon dioxide contents were determined by the method of Haldane.

The oxygen content of the blood was measured by the method of Van Slyke and Neill (4). Heparin was the anticoagulant used for hematocrit determinations. The peripheral resistance was recorded in absolute units by the formula:

$$
\mathrm{R}=\frac{\mathrm{Pm} \text { (mean pressure in } \mathrm{mm} . \mathrm{Hg}) \times 1332}{\text { C.O. (cardiac output in } \mathrm{ml} . \text { per sec.) }}
$$

\section{RESULTS}

Ten venesections were performed on 8 subjects, 3 experiments being carried out on 1 subject (Table I). In 5 of the experiments, the pulse rate and the cardiac output before venesection were within normal limits. In 5 , the circulation before venesection appeared hyperactive and it was believed that anxiety produced by the thought of blood loss accounted for the high pulse rate and the elevated cardiac output.

Effect of venesection in subjects with normal circulation. From 300 to $900 \mathrm{ml}$. of blood were removed from the subjects who appeared to be 
TABLE I

Observations on the effect of removal of 300 to $900 \mathrm{ml}$. of blood from normal subjects

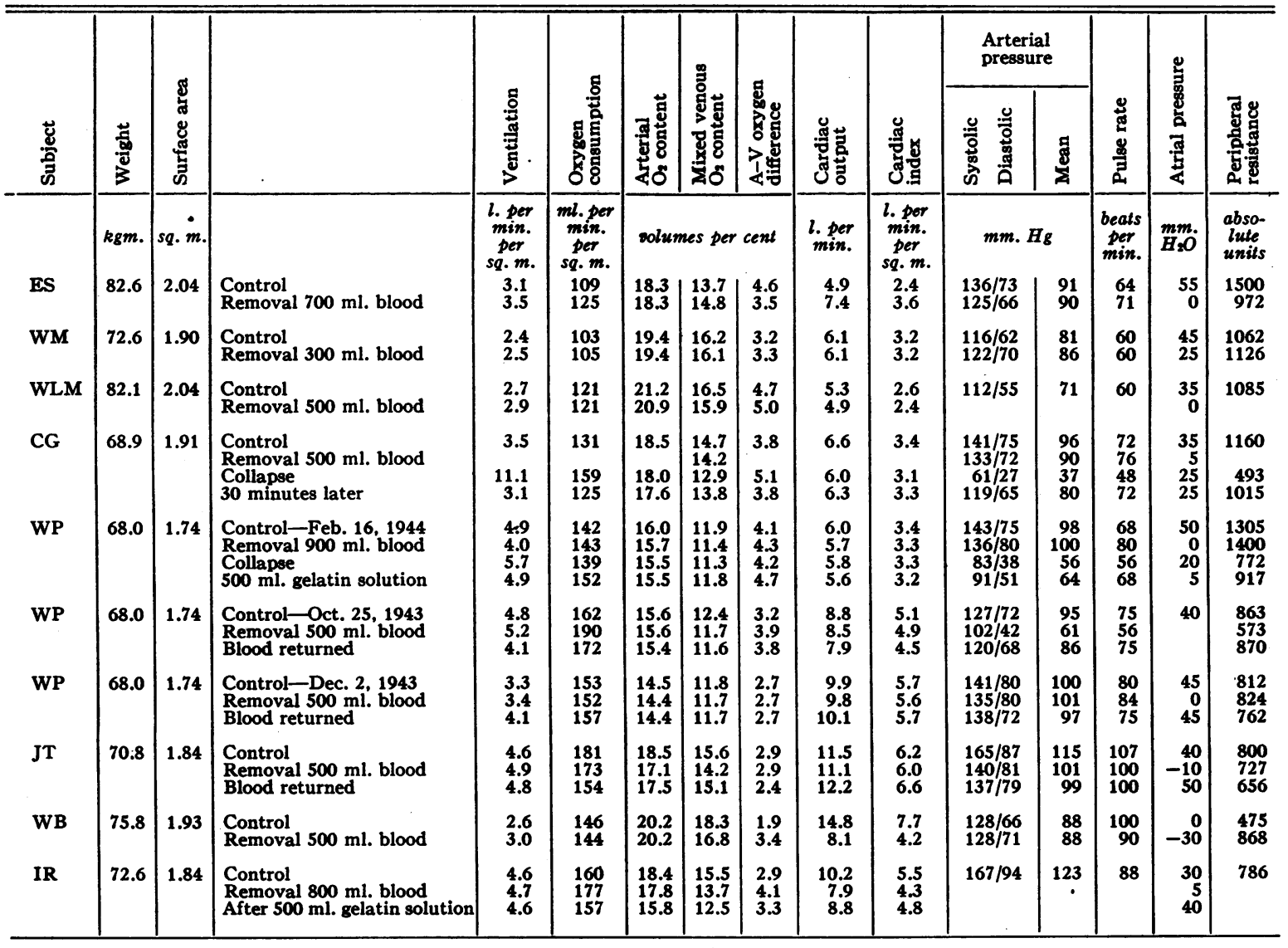

relaxed. The average decrease in atrial pressure was $38 \mathrm{~mm} . \mathrm{H}_{2} \mathrm{O}$. In subject $\mathrm{ES}$, after removal of $700 \mathrm{ml}$. of blood, the pulse rate increased 7 beats per minute and the oxygen consumption rose. The arteriovenous oxygen difference became less and the cardiac output was considerably increased in spite of a decrease in atrial pressure of $55 \mathrm{~mm}$. $\mathrm{H}_{2} \mathrm{O}$. The mean femoral arterial pressure did not change and the peripheral resistance was considerably decreased. It was felt that the rise in cardiac output resulted from apprehension induced by the removal of blood. In subject WM, only $300 \mathrm{ml}$. of blood were removed. The atrial pressure fell $20 \mathrm{~mm}$. $\mathrm{H}_{2} \mathrm{O}$, but there was no significant change in the arteriovenous oxygen difference, oxygen consumption, cardiac output, mean arterial pressure, or peripheral resistance. In subject WLM, the atrial pressure fell $35 \mathrm{~mm}$. $\mathrm{H}_{2} \mathrm{O}$ after the removal of $500 \mathrm{ml}$. of blood.
The arteriovenous oxygen difference increased 0.3 volume per cent and the cardiac output fell 0.4 liter per minute. These changes are not significant.

In subject $C G$, the atrial pressure fell $30 \mathrm{~mm}$. $\mathrm{H}_{2} \mathrm{O}$ after the removal of $500 \mathrm{ml}$. of blood. Immediately thereafter the heart rate had risen from 72 to 76 and the mean arterial pressure had fallen from 96 to $90 \mathrm{~mm}$. At this time, blood pressure cuffs which had been previously applied to the upper thighs were inflated to $80 \mathrm{~mm}$. $\mathrm{Hg}$. In a short time, the subject became pale and began to sweat. The tourniquets were immediately released, but the pallor became more marked and nausea began. The subject remained conscious, but he hyperventilated until his hands and feet felt numb. The heart rate had fallen to 48 beats per minute and the mean arterial pressure had decreased from 90 to $37 \mathrm{~mm}$. $\mathrm{Hg}$. The cardiac 
output had fallen irom 6.6 to 6.0. This is not a significant change. The peripheral resistance was strikingly lowered. Because of the hyperventilation, the atrial pressure reading was not entirely satisfactory. A reading of $25 \mathrm{~mm} . \mathrm{H}_{2} \mathrm{O}$ was recorded. This would mean a rise rather than a fall in atrial pressure during the circulatory collapse. Thirty minutes later the subject had recovered. The atrial pressure was $10 \mathrm{~mm}$. lower than the control reading and the mean arterial pressure remained appreciably depressed. The oxygen consumption had decreased, and the arteriovenous oxygen difference and the cardiac output were essentially the same as before the venesection.

Subject WP was being bled for the third time. The atrial pressure was lowered $50 \mathrm{~mm} . \mathrm{H}_{2} \mathrm{O}$ by a venesection of $900 \mathrm{ml}$. Observations made immediately after the removal of the blood showed no change in the circulation except a rise in pulse rate. Nine minutes later the subject became ashen, began to sweat, and complained of nausea. The atrial pressure rose above the level recorded immediately after bleeding. The heart rate slowed, the mean pressure fell from 100 to 56 $\mathrm{mm}$. $\mathrm{Hg}$, and the peripheral resistance decreased 50 per cent. The oxygen consumption, the arteriovenous oxygen difference and the cardiac output remained unchanged. Five hundred $\mathrm{ml}$. of gelatin solution were given intravenously. The patient developed urticaria and hemodilution did not occur. The atrial pressure remained low, the mean arterial pressure and the peripheral resistance were depressed, the metabolism rose somewhat, and the cardiac output remained unchanged.

Effect of venesection in subjects with hyperactive circulation. Five venesections were performed on 4 subjects who had hyperactive circulations before the venesections. Five hundred $\mathrm{ml}$. ( $800 \mathrm{ml}$. from IR) of blood were removed each time and the average fall in atrial pressure was $38 \mathrm{~mm}$. $\mathrm{H}_{2} \mathrm{O}$.

The first 2 experiments were carried out on subject WP. On October 25, 1943, the venesection was followed by acute circulatory collapse. This was not as severe as occurred in the same subject on February 16, 1944. The atrial pressure was not measured after the venesection. The metabolism rose, the arteriovenous oxygen differ- ence increased, and the cardiac output remained unchanged. As in the other 2 instances of acute circulatory collapse, the heart rate slowed, the systolic and diastolic pressures and the peripheral resistance fell. The blood was returned to the subject and measurements of the circulation showed the mean arterial pressure still to be somewhat depressed and the cardiac output to have fallen slightly. The change in cardiac output, which is probably not significant, may have been the result of progressive relaxation of the subject, rather than of a change in blood volume. On December 2, 1943, the experiment was repeated. The control cardiac output was greatly increased above the expected resting level. Venesection produced a fall in atrial pressure of 45 mm. $\mathrm{H}_{2} \mathrm{O}$ with an increase in heart rate of only 4 beats per minute. There was no change in cardiac output, mean arterial pressure, or peripheral resistance. The blood was returned without any significant change, except that the atrial pressure returned to the control level.

In subject JT, the removal of $500 \mathrm{ml}$. of blood caused a fall in atrial pressure of $50 \mathrm{~mm} . \mathrm{H}_{2} \mathrm{O}$ without any change in cardiac output. The heart rate decreased 7 beats per minute and the mean arterial pressure fell $14 \mathrm{~mm}$. Hg. These changes were attributed to lessened apprehension, rather than to changes in blood volume, because they persisted after the blood was returned to the subject and the atrial pressure had risen to the level prior to bleeding. There was a progressive fall in oxygen consumption which was attributed to lessening of anxiety.

In subject WB, the atrial pressure fell $30 \mathrm{~mm}$. $\mathrm{H}_{2} \mathrm{O}$. The heart rate decreased 10 beats per minute. The cardiac output fell from 14.8 to 8.1 liters per minute and the peripheral resistance doubled. It was felt that the high cardiac output, the fast pulse rate, and the low peripheral resistance were other manifestations of the nervous tension which the subject exhibited during the experiment. The question rose as to whether the cardiac output decreased because the atrial pressure decreased, or because the subject became more relaxed. Several months later the cardiac output was again measured under basal conditions. The heart rate was 82 beats per minute, the cardiac output was 7.6 liters per minute, and the peripheral resistance was 880 . These findings 
suggest that the change in cardiac output noted in the first experiment was caused by relaxation, rather than by the venesection.

In the eighth subject (IR), the atrial pressure fell $25 \mathrm{~mm} . \mathrm{H}_{2} \mathrm{O}$ and the cardiac output fell from 10.2 to 7.9 liters per minute. The cardiac output, after the venesection, was slightly above the expected resting value and again the question rose as to whether the fall resulted from the venesection or from relaxation because the venesection was completed. Five hundred $\mathrm{ml}$. of gelatin solution were given intravenously and the atrial pressure returned to the control level. The cardiac output was between the value obtained befcre and that obtained immediately after venesection.

Effects of venous tourniquets. In 4 subjects, studies on the circulation were made before and after the inflation of venous tourniquets applied to the proximal portions of the thighs. The pressure in the tourniquets ranged from 70 to 80 $\mathrm{mm}$. Hg. In subject $\mathrm{CB}$, the atrial pressure fell $50 \mathrm{~mm} . \mathrm{H}_{2} \mathrm{O}$. At the end of 10 minutes, the arteriovenous oxygen difference had increased and the cardiac output had decreased. The tourniquets were released and the atrial pressure returned to the control level. Fifteen minutes later, the arteriovenous oxygen difference and the cardiac output were at the level which they had reached while the tourniquets were inflated. In subject PM, the atrial pressure fell $35 \mathrm{~mm}$. The arteriovenous oxygen difference decreased and the cardiac output may have increased slightly. After the release of tourniquets, the changes in the arteriovenous oxygen difference and cardiac output persisted. In subject JC, the atrial pressure fell $40 \mathrm{~mm}$. The arteriovenous oxygen difference increased and the cardiac output tended to fall. In subject SL the atrial pressure fell 65 $\mathrm{mm}$. The metabolism increased so that the cardiac output was increased, though the arteriovenous oxygen difference remained unchanged.

The pooling of blood in the extremities produced a fall in atrial pressure equal to that produced by the removal of 500 to $1000 \mathrm{ml}$. of blood by venesection. This was to be expected from earlier data (6) which showed that between 500 and $900 \mathrm{ml}$. of blood may be pooled in 2 lower and 1 upper extremities by the use of venous tourniquets. As in the bleeding experiments, there was no demonstrable correlation between the atrial pressure and cardiac output. The data on subjects $C B$ and $P M$ demonstrate the fact that erroneous conclusions may be drawn unless determinations are made before, during, and after the application of the tourniquets to exclude psychic effects.

TABLE II

The effect on the circulation of pooling blood in the extremities by venous tourniquets

\begin{tabular}{|c|c|c|c|c|c|c|c|c|c|c|c|c|c|}
\hline 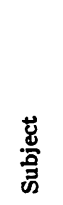 & $\begin{array}{l}\mathrm{H} \\
\frac{5}{3} \\
3\end{array}$ & 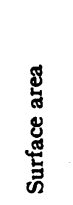 & & 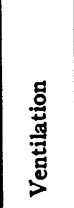 & 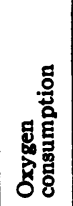 & 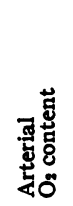 & 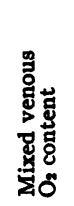 & 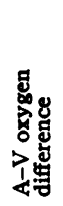 & 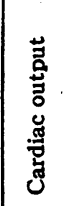 & 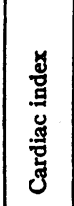 & $\begin{array}{c}\text { Arterial } \\
\text { pressure }\end{array}$ & 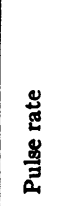 & 焉 \\
\hline & $\mathrm{kgm}$. & sq. $m$. & . & $\begin{array}{l}\text { l. per } \\
\text { min. } \\
\text { per } \\
\text { sq. } m .\end{array}$ & $\underset{\substack{\text { ml. } \\
\text { per } \\
\text { min. } \\
\text { per }}}{ }$ & \multicolumn{3}{|c|}{ volumes per cent } & $\begin{array}{l}\text { l. per } \\
\text { min. }\end{array}$ & $\begin{array}{l}\text { l. per } \\
\text { min. } \\
\text { per } \\
\text { sq. } m .\end{array}$ & $m m . \mathrm{Hg}$ & $\begin{array}{l}\text { beats } \\
\text { per } \\
\text { min. }\end{array}$ & $\mathrm{m}_{\mathbf{H}} \mathrm{O}$. \\
\hline CB & 68.9 & 1.90 & $\begin{array}{l}\text { Control } \\
\text { Tourniquets on } 10 \text { min. at } 70 \mathrm{~mm} . \mathrm{Hg} \\
15 \text { minutes after release }\end{array}$ & $\begin{array}{l}2.3 \\
2.3 \\
2.5\end{array}$ & $\begin{array}{l}123 \\
118 \\
127\end{array}$ & $\begin{array}{l}18.6 \\
19.2 \\
19.1\end{array}$ & $\begin{array}{l}15.6 \\
15.1 \\
14.9\end{array}$ & $\begin{array}{l}3.0 \\
4.1 \\
4.2\end{array}$ & $\begin{array}{l}7.8 \\
5.5 \\
5.7\end{array}$ & $\begin{array}{l}4.1 \\
2.9 \\
3.0\end{array}$ & $\begin{array}{l}120 / 70 \\
110 / 70 \\
112 / 70\end{array}$ & $\begin{array}{l}68 \\
72 \\
64\end{array}$ & $\begin{array}{r}40 \\
-10 \\
35\end{array}$ \\
\hline PM & 69.6 & 1.78 & $\begin{array}{l}\text { Control } \\
\text { Tourniquets on } 6 \text { min. at } 80 \mathrm{~mm} . \mathrm{Hg} \\
5 \text { minutes after release }\end{array}$ & $\begin{array}{l}3.8 \\
3.7\end{array}$ & $\begin{array}{l}143 \\
141\end{array}$ & $\begin{array}{l}19.6 \\
19.1 \\
19.3\end{array}$ & $\begin{array}{l}15.6 \\
15.5 \\
15.7\end{array}$ & $\begin{array}{l}4.0 \\
3.6 \\
3.6\end{array}$ & $\begin{array}{l}6.4 \\
6.9 \\
6.9\end{array}$ & $\begin{array}{l}3.6 \\
3.9 \\
3.9\end{array}$ & $120 / 64$ & 73 & $\begin{array}{r}25 \\
-10 \\
25\end{array}$ \\
\hline $\mathrm{JC}$ & 56.2 & 1.69 & $\begin{array}{l}\text { Control } \\
\text { Tourniquets on } 7 \mathrm{~min} \text {. at } 80 \mathrm{~mm} . \mathrm{Hg}\end{array}$ & $\begin{array}{l}4.0 \\
4.3\end{array}$ & $\begin{array}{l}130 \\
129\end{array}$ & $\begin{array}{l}18.5 \\
17.9\end{array}$ & $\begin{array}{l}13.8 \\
12.6\end{array}$ & $\begin{array}{l}4.7 \\
5.3\end{array}$ & $\begin{array}{l}4.7 \\
4.1\end{array}$ & $\begin{array}{l}2.8 \\
2.4\end{array}$ & $120 / 63$ & 58 & $\begin{array}{r}25 \\
-15\end{array}$ \\
\hline SL & 66.2 & 1.76 & $\begin{array}{l}\text { Control } \\
\text { Tourniquets on } 6 \mathrm{~min} \text {. at } 80 \mathrm{~mm} . \mathrm{Hg}\end{array}$ & $\begin{array}{l}3.0 \\
3.4\end{array}$ & $\begin{array}{l}114 \\
130\end{array}$ & $\begin{array}{l}16.8 \\
16.8\end{array}$ & $\begin{array}{l}13.5 \\
13.4\end{array}$ & $\begin{array}{l}3.3 \\
3.4\end{array}$ & $\begin{array}{l}6.2 \\
6.7\end{array}$ & $\begin{array}{l}3.5 \\
3.8\end{array}$ & & $\begin{array}{l}64 \\
64\end{array}$ & $\begin{array}{l}80 \\
15\end{array}$ \\
\hline
\end{tabular}




\section{DISCUSSION}

The removal of blood in 300 to $900 \mathrm{ml}$. quantities, by venesection or the pooling of blood in the extremities by venous tourniquets, caused a consistent fall in the atrial pressure. There was no close correlation between the removal or pooling of blood with any other function of the circulation which was measured. When the resting heart rate was slow, it usually rose slightly. The mean arterial pressure, the peripheral resistance, the arteriovenous oxygen difference, and the cardiac output showed no consistent changes. As pointed out previously, the method used in these studies is not sufficiently accurate to detect small changes in cardiac output; but no difficulty was encountered in demonstrating the 20 per cent decrease in cardiac output produced by tilting subjects to the erect position (10).

The question arose as to whether the effective atrial pressure actually fell as the blood was removed in moderate amounts. Could it be that the intrathoracic pressure showed a simultaneous fall as blood was removed, so that in spite of the apparent fall in atrial pressure the effective filling pressure remained unchanged? It has been shown that venous tourniquets decrease the amount of blood in the thorax (7). The intra. thoracic pressure was therefore measured directly in subject ES, who had previously been shown to have a decrease in atrial pressure without a fall in cardiac output. The application of venous tourniquets caused a fall in atrial pressure of 70 $\mathrm{mm} . \mathrm{H}_{2} \mathrm{O}$; the intrathoracic pressure varied between 0 and $-1 \mathrm{~cm}$. of $\mathrm{H}_{2} \mathrm{O}$ before and 0 and $-2 \mathrm{~cm} . \mathrm{H}_{2} \mathrm{O}$ after the inflation of the tourniquets. It was concluded, therefore, that the fall in atrial pressure was not compensated for by a considerable increase in negative intrathoracic pressure.

The atrial pressure was recorded optically by the method of Hamilton, before and after the venesection. The lowered mean pressure was not accompanied by a rise in the atrial systolic pressure.

From these data, it appears that the normal atrial pressure is somewhat in excess of that required to fill the ventricle at rest, and that, therefore, a moderate fall in atrial pressure can occur without any disturbance in cardiac output.
The fact that there was no evidence of generalized arteriolar vasoconstriction after the removal of a moderate amount of blood came as no surprise. Plethysmographic studies had failed to show any change in blood flow of the forearm as blood was pooled in the lower extremities by venous tourniquets (8). Furthermore, the fact that the ordinary donor suffers no inconvenience after the removal of $500 \mathrm{ml}$. of blood, and shows no clinical signs of poor tissue blood flow during the time his blood volume is depleted, is strong argument against a significant degree of arteriolar constriction with resultant ischemia of the tissues. Because of these observations, we taught our students that constriction of the veins and venules was the probable compensatory mechanism which maintained the atrial pressure and cardiac output at a constant level as the blood volume was decreased. To our surprise, it appears that no compensatory mechanism exists to maintain a constant atrial pressure within the observed limits. The heart seemed able to pump blood normally with a falling atrial pressure. This was true even when the cardiac output had been greatly elevated by anxiety. It is to be emphasized that these observations were all made on subjects from whom relatively small amounts of blood had been removed. In massive hemorrhage, various compensatory mechanisms and a fall in cardiac output can be demonstrated.

This lack of correlation between cardiac output and atrial pressure was noted in comparing the cardiac output of patients with severe anemia with that of normal subjects. A 100 per cent increase in cardiac output occurred without a significant change in atrial pressure (9). Likewise, in a study of normal subjects, it was noted that anxiety caused a striking rise in cardiac output without a rise in atrial pressure (10).

In a study of the effects of hemorrhage on normal subjects, certain investigators (11) found only slight changes in blood pressure, pulse rate, and ballistocardiograph tracing after the removal of 500 to $1000 \mathrm{ml}$. of blood. While they did not measure the atrial pressure, we can be certain from our observations that sufficient blood was removed to cause a significant lowering of pressure.

Other workers (12) reported that the removal 
of blood caused a parallel fall in cardiac output and atrial pressure. These authors used the catheter technique for obtaining blood samples and pressure readings from the right atrium. They also found that lowering of the atrial pressure by application of venous tourniquets to the thighs caused a parallel fall in atrial pressure and cardiac output. These same authors noted that epinephrine caused an increase in cardiac output in the presence of a falling venous pressure.

The acute circulatory collapse which developed on 3 occasions during our observations was characterized by a marked fall in systolic, diastolic, and mean arterial pressure, without a demonstrable change in cardiac output. The venous side of the circulation did not seem to be affected. In the one experiment in which satisfactory measurements were made repeatedly, the atrial pressure, with the onset of the circulatory collapse, increased above the level to which it had fallen immediately after the venesection. In 2 experiments, the arteriovenous oxygen difference increased, but as the oxygen consumption also increased, the cardiac output remained unchanged. It might be argued that the rise in metabolism without a corresponding rise in cardiac output produced a state of relative circulatory insufficiency, despite the fact that there was no actual fall in the cardiac output. In the third instance, however, the metabolism did not rise.

One worker (13) has made observations on the atrial pressure and cardiac output in one subject who developed acute circulatory collapse after the removal of $900 \mathrm{ml}$. of blood. "The blood pressure fell from 110 to 58 and the pulse from 82 to 50 . During the faint the right atrial pressure rose by $2 \mathrm{~cm}$. from the low level reached at the end of the hemorrhage. The cardiac output also rose slightly (3.2 to 3.6 liters per minute)." He concluded that this type of circulatory failure is due to a sudden loss of peripheral resistance (presumably arteriolar tone). Further observations on 7 subjects have supported this conclusion (14).

It is probable that the venesection had nothing to do with the circulatory collapse in the subjects reported here, except inasmuch as it served as a psychic and reflex stimulus. The data demonstrated that the venesection of this size does not cause a fall in cardiac output. Observations in many laboratories and blood donor centers have shown that this type of circulatory collapse frequently occurs before any blood is withdrawn.

Because of the marked fall in arterial pressure and the striking pallor, we were surprised to find that the cardiac output had not fallen. The fact that the cardiac output with the subject in the horizontal position remained unchanged with acute circulatory collapse may be the reason that this type of circulatory disturbance is so benign. On standing, these subjects are very apt to lose consciousness. Whether this results from a more striking arteriolar dilatation with too low a pressure to raise blood to the head, or from venous pooling with a subsequent fall in atrial pressure and a further decreased arterial pressure, because of a drop in cardiac output, has not been determined.

The question arises as to whether the fall in arterial pressure causes the pallor, epigastric distress, sweating, weakness, and nausea, or whether both the decrease in arterial pressure and the other symptoms are the result of intense stimulation of the autonomic nervous system from reflexes arising either in a part of the body or from emotional content of thought. Clinical observations have shown that the pallor, epigastric distress, sweating, weakness, and slow pulse rate may, or may not, be accompanied by a marked fall in arterial pressure. It has also been noted that these symptoms may persist long after the arterial pressure has returned to normal or has been raised by the administration of vasoconstrictor drugs. The sudden circulatory failure produced by heart block from organic disease, or by cardiac standstill from carotid sinus pressure, is not associated with nausea or sweating, though moderate pallor may occur. Patients with true orthostatic hypotension have a striking fall in arterial pressure when they stand, which may be sufficiently severe to cause unconsciousness. This fall in arterial pressure is a true postural effect and is not appreciably influenced by emotional stimuli. These patients do not show pallor, sweating, or nausea as the arterial pressure falls (15). After an anaphylactic reaction or after a bout of fever, the arterial pressure may be markedly lowered without the other symptoms which commonly occur with acute circulatory collapse. All of these observations support the assumption that the entire syndrome 
of pallor, nausea, weakness, sweating, slow pulse rate, and fall in arterial pressure results from reflex stimulation of the autonomic nervous system and that the fall in arterial pressure accompanies, rather than causes, the other symptoms.

The above hypothesis does not explain certain other observations. Standing upright makes subjects much more likely to have acute circulatory collapse. Indeed, after the collapse has occurred and the patient has recovered in the horizontal position, it is frequently possible to reproduce the syndrome by motionless standing. Furthermore, in patients who have bled profusely, syncope can be easily induced by tilting the subject with the feet down. It is usually preceded by pallor, sweating, nausea, and a sharp fall in arterial pressure. In the past, we have wondered whether the symptoms, as well as the syncope, were produced by cerebral ischemia, resulting from a diminished cardiac output because of a decreased venous return secondary to venous pooling from gravity. It may be that the situation is much more complex and that under certain conditions standing causes an increase in activity of the autonomic nervous system, irrespective of a fall in cardiac output. If this produced a marked decrease in peripheral resistance and the arterial pressure became very low, syncope would occur from cerebral ischemia. This problem needs further study.

The realization that the circulatory collapse with the subject in the horizontal position is primarily a sudden reflex loss of peripheral resistance, and not circulatory failure secondary to a decrease in venous return, stimulates one to renew the search for effective drug therapy to prevent its occurrence in donors. Our impression is that a trial of therapy directed toward a lessening of generalized autonomic activity, rather than toward a production of arteriolar constriction, would be worthwhile.

\section{SUMMARY AND CONCLUSIONS}

1. The effect on the circulation of the removal of 300 to $900 \mathrm{ml}$. of blood by venesection and the effect of pooling of blood in the extremities by the venous tourniquets were studied in 12 normal males. The atrial pressure readings and the samples of mixed venous blood for measuring the cardiac output were obtained through a catheter introduced into the right atrium by way of the antecubital vein. The femoral arterial pressure was recorded optically.

2. Venesection and the application of venous tourniquets caused a fall in atrial pressure from 20 to $65 \mathrm{~mm}$. $\mathrm{H}_{2} \mathrm{O}$. There was no consistent change in cardiac output, mean arterial pressure, or peripheral resistance. Returning the blood by transfusion or by releasing the venous tourniquets was followed by a return of the atrial pressure to the control level without any change in the cardiac output.

3. The data suggest that the normal atrial pressure with the subject in the recumbent position is somewhat in excess of that required to fill the ventricles and that a decrease in blood volume of the degree reported here produces a lowering of atrial pressure without interfering with ventricular filling. These observations obviously do not apply to massive hemorrhage.

4. Acute circulatory collapse appeared in 3 instances. The subjects became pale, sweated profusely, and complained of nausea and weakness. The pulse rate slowed strikingly. The atrial pressure increased, the cardiac output remained unchanged. There was a marked fall in the arterial pressure and peripheral resistance. The circulatory collapse appeared to be the result of a sudden decrease in peripheral resistance because of reflex vasodilatation, presumably in the arterioles. There was no evidence of a decreased venous return.

This work was done with the technical assistance of Miss Maurine Giese, Miss Eloise Cavin, Mrs. Janet Stegeman, and Mrs. Jane Bailey.

\section{BIBLIOGRAPHY}

1. Cournand, A., and Ranges, H. A., Catheterization of the right auricle in man. Proc. Soc. Exper. Biol. and Med., 1941, 46, 462.

2. Goldring, W., and Chasis, H., Hypertension and Hypertensive Disease. Appendix B, The Commonwealth Fund, New York, 1944.

3. Hamilton, W. F., Brewer, G., and Brotman, I., Pressure pulse contours in the intact animal. I. Analytical description of a new high-frequency hypodermic manometer. Am. J. Physiol., 1934, 107, 427.

4. Van Slyke, D. D., and Neill, J. M., The determination of gases in blood and other solutions by 
vacuum extraction and manometric measurement. J. Biol. Chem., 1924, 61, 523.

5. Cournand, A., Riley, R. L., Bradley, S. E., Breed, E. S., Noble, R. P., Lauson, H. D., Gregerson, M. I., and Richards, D. W., Studies of the circulation in clinical shock. Surgery, 1943, 13, 964.

6. Ebert, R. V., and Stead, E. A., Jr., The effect of the application of tourniquets on the hemodynamics of the circulation. J. Clin. Invest., 1940, 19, 561.

7. Hamilton, W. F., and Morgan, A. B., Mechanism of postural reduction in vital capacity in relation to orthopnea and storage of blood in lungs. Am. J. Physiol., 1932, 99, 526.

8. Warren, J. V., and Stead, E. A., Jr., Unpublished observations.

9. Brannon, E. S., Merrill, A. J., Warren, J. V., and Stead, E. A., Jr., The cardiac output in patients with chronic anemia as measured by the technique of right atrial catheterization. J. Clin. Invest., 1945, 24, 332.

10. Stead, E. A., Jr., Warren, J. V., Merrill, A. J., and
Brannon, E. S., The cardiac output in male subjects as measured by the technique of right atrial catheterization. Normal values with observations on the effect of anxiety and tilting. J. Clin. Invest., 1945, 24, 326.

11. Shenkin, H. A., Cheney, R. H., Govons, S. R., and Starr, I., Effects of acute hemorrhage of known amount on the circulation of essentially normal persons. Am. J. M. Sc., 1943, 206, 806.

12. McMichael, J., and Sharpey-Schafer, E. P., Cardiac output in man by a direct Fick method. Brit. Heart J., 1944, 6, 33.

13. McMichael, J., Clinical aspects of shock. J. A. M. A., 1944, 124, 275.

14. Barcroft, H., Edholm, O. G., McMichael, J., SharpeySchafer, E. P., Posthaemorrhagic fainting: study by cardiac output and forearm flow. Lancet, 1944, 1, 489.

15. Stead, E. A., Jr., and Ebert, R. V., Postural hypotension; a disease of the sympathetic nervous system. Arch. Int. Med., 1941, 67, 546. 